\title{
Influence of Resin Solvent on Color and Surface Roughness of Aesthetic Restorative Materials
}

\author{
Inas A Elghandour
}

\begin{abstract}
Aim: The aim of the study was to ascertain the influence of a resin remover on color and surface roughness of two resin composites. Materials and methods: Disc-shaped specimens were fabricated from either a Te-Econom plus microhybrid or a Tetric EvoCeram nanocomposite. The color and surface roughness of the specimens were measured before and after treatment, with a resin remover for 3, 5, and 8 minutes. The color was measured using a reflective spectrophotometer according to the CIE $L^{*} a^{*} b^{*}$ color space measurements. Surface roughness was evaluated using optical profilometry. Results were statistically analyzed using Student's $t$ test, ANOVA, Tukey's post hoc, and Pearson's correlation tests.

Results: The resin remover induced a statistically significant color change of both resin composites, which increased with increasing the time of immersion to 8 minutes. The color change of Tetric EvoCeram was higher than that of the Te-Econom Plus. Surface roughness change was more pronounced with Tetric EvoCeram. No correlation was found between changes in color and surface roughness.

Conclusion: Resin solvent changed the color of microhybrid and nanocomposite. Increasing the immersion time to 8 minutes increased the color change. The type of composite influenced the changes in color and surface roughness.

Clinical significance: Resin solvent had potentials to stain resin composites, which could be helpful in its identification from tooth structure during removal of failed resin composite restorations.

Keywords: Color change, Detection of resin composites, Laboratory research, Resin composite, Resin remover, Resin solvent, Surface roughness. The Journal of Contemporary Dental Practice (2019): 10.5005/jp-journals-10024-2628
\end{abstract}

\section{INTRODUCTION}

Resin composites are considered nowadays the material of choice for esthetic replacement of defective hard tooth structures. ${ }^{1}$ Restorations made with recent composite resins represent a diagnostic challenge, where clinical visualization of composite using conventional diagnostic procedures is practically difficult. The similarity of shades of resin composites to the surrounding teeth and the dark oral environment limits the ability of the dentist for better inspection of the restored teeth. The demand for other diagnostic methods for detecting esthetic composite restorations is growing. In addition, there is an increasing need for more clinically feasible techniques that help selectively remove esthetic restorative materials from teeth during replacement of failed restorations or post orthodontic treatment. ${ }^{2-4}$

New composite, compomer and ceramic restorative materials reproduce the esthetic qualities of natural hard tissue as perfectly as possible. Previous researchers had attempted several methods to detect resin composites. Usage of dyes as ink and 0.2 brilliant green solution have been examined in forensic dental identification. ${ }^{5}$ These dyes showed toxic properties and were not approved by FDA. ${ }^{5}$ Fluorescence-inducing diagnostic devices were tried to visually differentiate between esthetic fillings and tooth structure depending on differences in fluorescence properties between composites and dental substrate. ${ }^{6}$ Tani et al. found that resin composites emit weaker fluorescence than tooth structure on using excitation wavelengths longer than $430 \mathrm{~nm} .{ }^{3}$ Meller and Klein found that nearly $80 \%$ of resin composites showed more fluorescence than enamel and dentin. ${ }^{7}$ Meller and Klein found that the maximum fluorescence induction could be reached for all the shades of 16 brand of resin composites, if stimulated by an illumination light source between 395 and $405 \mathrm{~nm}$ wavelength. ${ }^{8}$ However, the fluorescence emission needs a dark environment for better visualization, which is difficult in clinical settings. ${ }^{9}$ Abdallah et al.
Restorative Dental Science Department, College of Dentistry, Imam Abdul Rahman Bin Faisal University, Dammam, Kingdom of Saudi Arabia; Operative Dentistry Department, Faculty of Dentistry, Cairo University, Cairo, Egypt

Corresponding Author: Inas A Elghandour, Restorative Dental Science Department, College of Dentistry, Imam Abdul Rahman Bin Faisal University, Dammam, Kingdom of Saudi Arabia, Phone: +966 542312172, e-mail: ielghandour@iau.edu.sa

How to cite this article: Elghandour IA. Influence of Resin Solvent on Color and Surface Roughness of Aesthetic Restorative Materials. J Contemp Dent Pract 2019;20(8):901-906.

Source of support: Nil

Conflict of interest: None

attempted to develop a solution that stains composites selectively than enamel surface. They found that intact teeth are stained using oil red, which is hydrophobic. Acetone-washed teeth were stained by methylene blue. Resin composites were stained using oil red, turmeric, paprika, and turmeric/methylene blue combinations. ${ }^{10}$

Other techniques to differentiate between resin composites and dental tissue are still required. Resin removers are used to remove resin-based endodontic filling, as recommended by the manufacturer. Therefore, a question arises: If it could affect resin components of filling, would it be feasible to be used to stain a resin composite or not? Accordingly, in the present study, the effect of a resin remover on the color of two resin composites was examined. Since surface roughness could affect color change, ${ }^{11}$ the change in surface roughness induced by the resin remover was also measured to further explore its influence. The first hypothesis is that a resin remover would affect the color and surface roughness of resin composites. The second hypothesis is that increasing time 
Table 1: Description of materials

\begin{tabular}{|c|c|c|}
\hline Material & Chemical composition & Manufacturer \\
\hline \multirow{2}{*}{$\begin{array}{l}\text { Te-Econom plus } \\
\text { microhybrid composite }\end{array}$} & Matrix; dimethacrylate and TEGDMA (22 wt\%) & Ivoclar Vivadent AG, Schaan, Liechtenstein \\
\hline & $\begin{array}{l}\text { Fillers; barium glass, silicon dioxide, mixed oxide and ytterbium } \\
\text { trifluoride ( } 76 \text { wt\% or } 60 \text { vol\%). The filler size range from } 0.04 \text { to } \\
7 \mu \mathrm{m} \text { with an average particle size of } 850 \mathrm{~nm} \text {. Initiators, } \\
\text { stabilizers, additives, and pigments ( } 2 \mathrm{wt} \% \text { ) }\end{array}$ & \\
\hline \multirow{2}{*}{$\begin{array}{l}\text { Tetric EvoCeram } \\
\text { nanohybrid resin } \\
\text { composite }\end{array}$} & Matrix; dimethacrylates (17-18 wt\%) & Ivoclar Vivadent AG, Schaan, Liechtenstein \\
\hline & $\begin{array}{l}\text { Fillers; barium glass, copolymers, mixed oxide and ytterbium } \\
\text { trifluoride ( } 82-83 \mathrm{wt} \%) \text {. Filler content is } 75-76 \mathrm{wt} \% \text { or } 53-55 \mathrm{vol} \% \text {. } \\
\text { The particle sizes range between } 40 \mathrm{~nm} \text { and } 3 \mu \mathrm{m} \text {. Additives, } \\
\text { initiators, stabilizers, and pigments are additional ingredients }\end{array}$ & \\
\hline Resin remover & $\begin{array}{l}\text { Oil of citronella } 15 \%, N, N \text {-dimethylformamide } 15 \% \text {, tincture of } \\
\text { benzoin } 5 \% \text {, essential oils } 4.6 \% \text {, tolu balsam } 5 \% \text {, excipient ad } 100 \%\end{array}$ & $\begin{array}{l}\text { Produits Dentaries SA, 1800Vevey, } \\
\text { Switzerland }\end{array}$ \\
\hline
\end{tabular}

of application of a resin remover would increase its influence on the color and surface roughness of resin composites. The third hypothesis is that there is a correlation between the surface roughness and the color of resin composites.

\section{Materials and Methods}

\section{Materials}

Two types of resin composites were examined: a microhybrid Te-Econom plus and a nanohybrid Tetric EvoCeram. For both materials, shade A3 was selected. Composition of restorative materials is shown in Table 1.

\section{Methods}

Twenty specimens were fabricated at the Research center of College of Dentistry, Imam Abdul Rahman Bin Faisal University, Kingdom of Saudi Arabia. Ten disc-shaped specimens were prepared from a microhybrid composite Te-Econom plus and the other ten from a nanohybrid composite Tetric EvoCeram. A clear plastic mold of dimensions $5 \mathrm{~mm}$ diameter $\times 2 \mathrm{~mm}$ height was used for specimens' fabrication. Materials were used following manufacturers' instructions. For both tested materials, the resin composite was packed inside the mold as one increment. A mylar strip was applied on the composite surface and a glass slab was pressed over it to extrude the excess material. The material was cured using a LEDition curing unit with a light intensity of $600 \mathrm{~mW} / \mathrm{cm}^{2}$ (Ivoclar Vivadent $^{\mathrm{TM}}$, Schaan, Liechtenstein) for 40 seconds. The light had a wavelength range of $430-490 \mathrm{~nm}$. The tip of the curing unit was positioned in such a way that it contacts the surface of the slab. After curing the top surface, the bottom surface was cured with light for 40 seconds. Samples were removed from the mold and polished using Soflex discs (3M ESPE, St. Paul, MN, USA) under air-water spray with a slow-speed handpiece. They were stored in water for 1 week at room temperature before testing and treatment with a resin remover.

\section{Treatment of Specimens with Resin Remover}

Before treatment with the resin remover, the color and surface roughness of specimens were measured as described below. Each specimen was immersed in a resin solvent [Produits Dentaires SA, 1800 Vevey, Switzerland] for 3 minutes at room temperature. The quantity of the resin remover was adjusted to cover the whole surface of the specimen. Samples were rinsed with water and measured for surface roughness and color to determine any changes. They were then subjected to an additional 2-minutes immersion in a resin remover to produce a total of 5-minutes immersion time. They were rinsed, dried, and changes in the surface roughness and color were measured again. Then, specimens were subjected to another 3-minutes immersion inside the resin remover to provide 8-minutes total immersion time and again the surface roughness and color were evaluated and changes were calculated.

\section{Color Measurement}

A portable reflective spectrophotometer was used to measure the specimens' colors (X-Rite, model RM200QC, Neu-Isenburg, Germany) (Fig. 1). Specimens were exactly lined up with the device and the aperture size was adjusted to $4 \mathrm{~mm}$. A white background was chosen, and the color was measured according to the CIE $L^{*} a^{*} b^{*}$ color system in relation to the CIE standard illuminant D65. The CIELAB system is a chromatic value color space that measures the value and chroma on three coordinates: $a^{*}$ represents color in the green $\left(a^{*}<0\right)$ and red dimension $\left(a^{*}>0\right) ; b^{*}$ represents color in the blue $\left(b^{*}<0\right)$ and yellow $\left(b^{*}>0\right)$ dimension s and $L^{*}$ represents the color lightness measured from black $\left(L^{*}=0\right)$ to white $\left(L^{*}=100\right)$. A single operator previously calibrated made all measurements in the same environment. The changes in color $(\Delta E)$ of the specimens were evaluated using the following formula:

$$
\Delta E_{\mathrm{CIELAB}}=(\Delta L * 2+\Delta a * 2+\Delta b * 2) \frac{1}{2}
$$

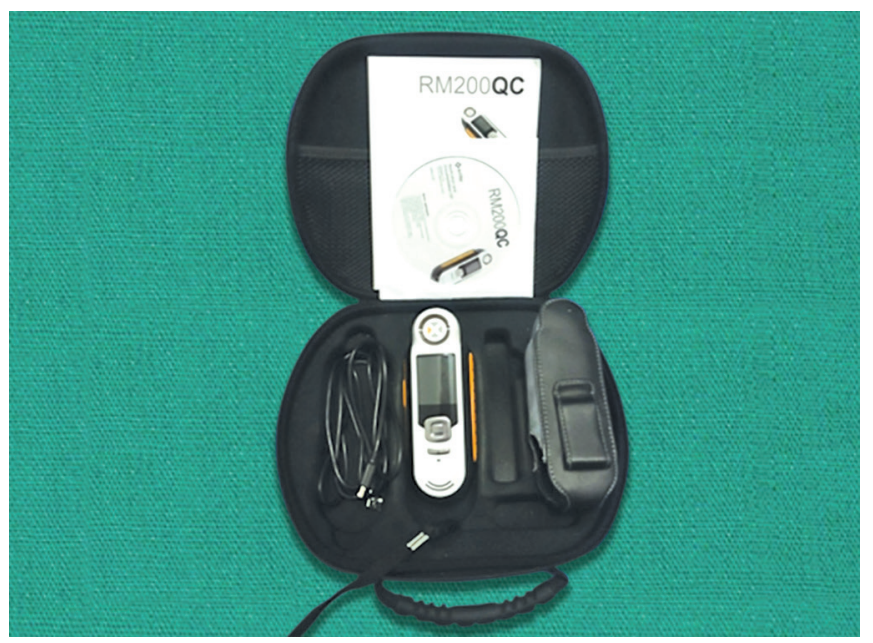

Fig. 1: Portable reflective spectrophotometer (X-Rite, model RM200QC, Neu-Isenburg, Germany) 
where $L^{*}=$ lightness $(0-100), a^{*}=$ (color changes in the red/ green axis), and $b^{*}=$ (color change in the yellow/blue axis). ${ }^{12} \mathrm{~A}$ limit of $\Delta E<1$ is invisible, and $\Delta E>1$ is visible to the professional dentist but not to the non-dental staff; $\triangle E a b^{*}=3.3$ is considered the clinically detectable and unacceptable level..$^{13,14}$ The color of specimens was measured before and after treatment with the resin remover for 3,5 , and 8 minutes. The degree of color change $[\Delta E]$ was then calculated.

\section{Measurement of Surface Roughness}

Measurements of surface roughness was made using optical profilometry for quantitative description of surface topography without contact. ${ }^{15}$ A quantitative analysis of the surface of the specimens was carried out in a 3D-surface analyzer system. A digital microscope with a built-in camera and connected with an IBM compatible personal computer was used to photograph specimens' surface (Scope Capture Digital Microscope, Guangdong, China). Measurements were made under standardized magnification of $120 \times$. A resolution of $1280 \times 1024$ pixels was selected to record images. In order to standardize the area of roughness measurement, the digital images were cropped to $350 \times 400$ pixels using Microsoft office picture manager. ${ }^{16} \mathrm{WS} \times \mathrm{M}$ software (Ver 5 develop 4.1, Nanotec, Electronica, SL) was used to analyze cropped images. ${ }^{17}$ All limits, frames, sizes, and measured parameters are expressed in pixels within the WSxM software. System calibration was made to transform pixels into absolute units. Calibration was made by comparing a ruler of standard size with a scale generated by the software. Average of heights (Ra) expressed in $\mu \mathrm{m}$ was then calculated. ${ }^{18}$ Subsequently, a digital image analysis system (Image J 1.43U, National Institute of Health, USA) was used to create a 3D image of the surface profile of specimens. The untreated surface served as a reference. With this method, a three-dimensional geometry of the surface was generated. Measurements of surface roughness were undertaken before and after the treatment with the resin remover for 3, 5, and 8 minutes.

\section{Statistical Analysis}

Data values were presented as mean and standard deviation (SD). Data were tested for normality by checking the data distribution and using Kolmogorov-Smirnov and Shapiro-Wilk tests. Student's $t$ test and ANOVA were used to study the effect of different resin composites and immersion times on mean values. When the ANOVA test is significant, Tukey's post hoc test was used for pair-wise comparisons. The correlation between color change and roughness change was detected by Pearson's correlation. $p$ values $\leq 0.05$ are considered statistically significant for all tests and $95 \%$ confidence interval. The statistical analysis was performed using Graph Pad Instat (Graph Pad, Inc.) software for windows.

\section{Results \\ Color Change}

Color change $(\Delta E)$ results (mean $\pm \mathrm{SD}$ ) for the Te-Econom plus and the Tetric EvoCeram after different immersion times in the resin remover are listed in Table 2. After immersion in the resin remover, the color of both Tetric EvoCeram and Te-Econom group showed a significant change, which was clinically unacceptable after 8 minutes immersion (Fig. 2). However, after 3 and 5 minutes, the change was in the clinically detectable but acceptable range for Te-Econom and in the clinically unacceptable range for the Tetric Evo Ceram.

A statistical comparison of the effect of immersion time on the color change of studied resin composites revealed that 8-minutes immersion in the resin remover showed the highest statistically significant color change at $p$ value $<0.05$. This was followed by 3-minutes immersion and lastly 5 -minutes immersion as revealed by the one-way ANOVA test. However, the difference between 3- and 5-minutes immersions was statistically significant for the Te-Econom resin composite and statistically non-significant for the Tetric EvoCeram resin composite as shown by Tukey's pair-wise post hoc test.

A statistical comparison of differences in the color change between two resin composites showed that the Tetric EvoCeram resin composites group recorded a higher color change compared to the Te-Econom resin composite. The difference was statistically non-significant $(p>0.05)$ after 3-minutes and 8-minutes immersion time. However, after 5 minutes' immersion time, the difference was statistically significant at $p<0.05$.

\section{Changes in Surface Roughness}

Surface roughness values (Ra) (mean \pm SD) for both resin composites groups before and after immersion in the resin remover for different times are summarized in Table 3. After immersion in the resin remover, the changes in surface roughness of Te-Econom was statistically non-significant at $p$ value $>0.05$ as revealed by one-way ANOVA test regardless of the immersion time. For Tetric EvoCeram group, it was found that the baseline subgroup recorded a statistically significant $(p<0.05$ ) highest roughness mean value followed by 5 minutes in the treatment solution subgroup and then 8 minutes in the treatment solution subgroup while the lowest roughness mean value recorded with the 3-minutes immersion subgroup as revealed by the one-way ANOVA test. Turkey's pair-wise post hoc test showed a non-significant $(p>0.05)$ difference between the baseline and 5-minutes subgroups. Also, non-significant difference $(p>0.05)$ was found between 3-minutes and 8-minutes subgroups.

A comparison of the surface roughness of the studied resin composite at each immersion period revealed that at the baseline, 5 , and 8 minutes, the differences in surface roughness of both

Table 2: Color change results (mean \pm SD) for both resin composites groups after different immersion times in the resin remover

\begin{tabular}{|c|c|c|c|c|c|c|}
\hline \multirow[b]{2}{*}{ Variables } & & \multicolumn{2}{|c|}{ Te Econom resin composite } & \multicolumn{2}{|c|}{ Tetric EvoCeram resin composite } & \multirow{2}{*}{$\frac{\text { Statistics }}{p \text { value }}$} \\
\hline & & Mean & $S D$ & Mean & $S D$ & \\
\hline \multirow[t]{3}{*}{ Time of immersion } & Three minutes & $2.582143^{b}$ & 0.617666 & $3.343701^{b}$ & 1.402978 & $0.2481 \mathrm{~ns}$ \\
\hline & Five minutes & $1.658201^{c}$ & 0.59591 & $3.253885^{\mathrm{b}}$ & 1.377873 & $0.0209^{*}$ \\
\hline & Eight minutes & $3.699774^{\mathrm{a}}$ & 0.637582 & $4.925544^{\mathrm{a}}$ & 1.509006 & $0.0621 \mathrm{~ns}$ \\
\hline Statistics & $p$ value & $<0.0001^{*}$ & & $0.0058^{*}$ & & \\
\hline
\end{tabular}

Different superscripts in the same column denote significant difference $(p<0.05)$; ns, non-significant $(p>0.05) ;{ }^{*}$, significant $(p<0.05)$ 


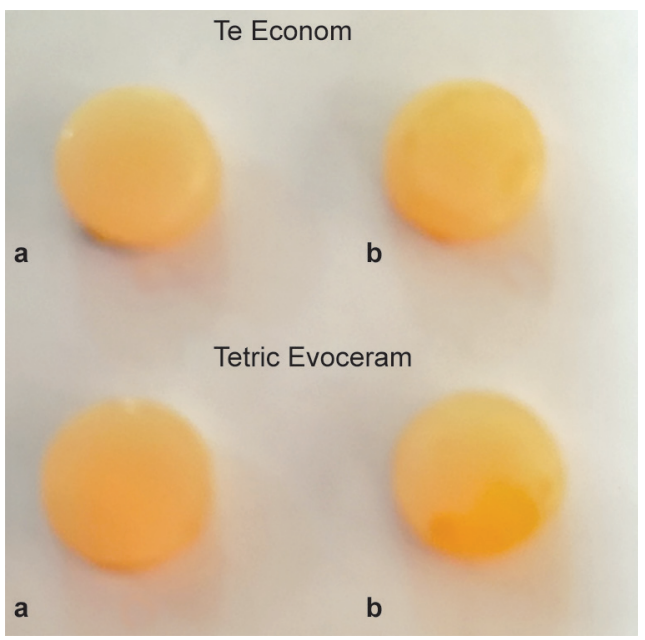

Figs $2 \mathrm{~A}$ and B: Te-Econom and Tetric EvoCeram specimens; (A) Before treatment; (B) After treatment with resin remover for 8 minutes

materials was statistically non-significant at $p$ value $>0.05$ as revealed with the un-paired $t$ test. However, after 3-minutes immersion in the resin remover, the Te-Econom resin composite recorded a statistically significantly higher mean surface roughness compared to the Tetric EvoCeram. The difference was statistically significant at $p$ value $<0.05$ as revealed with the un-paired $t$ test. A statistical comparison of surface roughness of both materials regardless of immersion in the resin remover showed that the Te-Econom recorded statistically non-significant $(p=0.3384>$ 0.05 ) differences in mean roughness values compared to the Tetric EvoCeram as revealed by the two-way ANOVA test.

\section{Correlation between roughness $(\mathrm{Ra})$ and color change $(\Delta E)$}

The Pearson's correlation coefficient $(r)$ scaled from -1 to 1. Negative values denote a negative correlation, positive values denote a positive correlation, and zero value indicates no correlation. In addition, $r$ values near to -1 or +1 denote a strong negative or positive correlation, respectively, whereas $r$ values remote from -1 or +1 indicate a weak negative and positive correlation, respectively. The correlation between color change and surface roughness change was non-significant as revealed by Pearson correlation $\left(r=0.3466, r^{2}=0.1201, p<0.05\right)$ and shown in Figure 3.

\section{Discussion}

Color is assessed in dentistry by two methods: instrumental and visual. Instrumental colorimetry reduces subjective errors during color assessment and measures slight color differences compared to naked eyes. ${ }^{19}$ The CIE Lab system was found appropriate to determine small differences in color. ${ }^{20,21}$ In the present study, a $\Delta E$ 3.3 was considered as an unacceptable clinical level. ${ }^{22}$ However, during removal of failed restoration, even a value of $\Delta E 1$ is sufficient for a professional dentist to identify the restoration from the tooth. ${ }^{21}$ Surface texture could affect color of the restoration as it affects light reflection. ${ }^{23,24}$ Therefore, all specimens were polished with Soflex discs for standardization purpose. Measurements of surface roughness was made in the present study using optical profilometry without contact in order to provide 3D surface analysis at the nanometer level without damage to the surface. ${ }^{15,25}$ Specimens were stored for one week before measurement as most water sorption and staining susceptibility was found to occur during the first week. ${ }^{26}$ The staining periods tested were 3,5 , and 8 minutes following the manufacturer's instructions and to simulate a clinical situation.

In the present study, both Tetric EvoCeram and Te-Econom group showed clinically unacceptable discoloration after 8-minutes immersion in the resin remover. The staining of Te-Econom might be caused by its content of triethylene glycol dimethacrylate (TEGDMA). The presence of the ethoxy group in TEGDMA (which is hydrophilic) might lead to an increased water sorption, allowing penetration of water into the matrix or filler-matrix interface and hence an increased susceptibility to environmental stains. ${ }^{27}$ The Tetric EvoCeram contains copolymer fillers; hence, the resin remover would affect the resin matrix in addition to filler components with a subsequent more penetration inside the composite. This was in accordance with the study of Telang et al. ${ }^{28}$ Increased time of immersion till 8 minutes increased significantly the color change. This agreed with that reported by other researchers. ${ }^{29,30}$ The surface roughness recorded in the present study is above $0.2 \mu \mathrm{m}$. Some studies reported a surface roughness value of $0.2 \mu \mathrm{m}$ to be the threshold at which plaque accumulation occurs. Accordingly, it might allow stain adsorption for both materials. ${ }^{31}$

In the present study, regardless of the treatment solution, it was found that Tetric EvoCeram resin composites revealed a higher color change compared to the microhybrid Te-Econom resin composite. The Te-Econom contains TEGDMA, which is absent in the Tetric evo ceram. Although Te-Econom contains a more hydrophilic component, it showed better stain resistance. This might be due to a better degree of polymerization, where TEGDMA was shown to improve the degree of conversion. ${ }^{32}$ This result is in agreement with other researchers who reported that composites having a smaller filler size not necessarily reveal lower staining. ${ }^{33,34}$ On the other hand, the results opposed the findings of other researchers who found that TEGDMA-containing composites showed more staining than TEGDMA-free resin composites. ${ }^{35,36}$ In the present study, although both materials were eventually discolored, the rate

Table 3: Surface roughness $(\mu \mathrm{m})$ (mean \pm SD) for both resin composites groups before and after different immersion times in the resin remover

\begin{tabular}{|c|c|c|c|c|c|c|}
\hline \multirow[b]{2}{*}{ Variables } & & \multicolumn{2}{|c|}{ Te-Econom resin composite } & \multicolumn{2}{|c|}{ Tetric EvoCeram resin composite } & \multirow{2}{*}{$\begin{array}{l}\text { Statistics } \\
p \text { value }\end{array}$} \\
\hline & & Mean & $S D$ & Mean & $S D$ & \\
\hline \multirow{4}{*}{$\begin{array}{l}\text { Treatment solution } \\
\text { time }\end{array}$} & Baseline & $0.257057^{a}$ & 0.002575 & $0.257627^{a}$ & 0.00178 & $0.6650 \mathrm{~ns}$ \\
\hline & Three minutes & $0.257137^{\mathrm{a}}$ & 0.001585 & $0.25507^{\mathrm{b}}$ & 0.00199 & $0.0428^{*}$ \\
\hline & Five minutes & $0.256513^{\mathrm{a}}$ & 0.001719 & $0.257083^{\mathrm{a}}$ & 0.002107 & $0.6083 \mathrm{~ns}$ \\
\hline & Eight minutes & $0.25692^{\mathrm{a}}$ & 0.001696 & $0.255797^{\mathrm{b}}$ & 0.001396 & $0.2123 \mathrm{~ns}$ \\
\hline Statistics & $p$ value & $0.9519 \mathrm{~ns}$ & & $0.0421^{*}$ & & \\
\hline
\end{tabular}

Different superscript's in the same column denote significant difference $(p<0.05)$; ns, non-significant $(p>0.05) ;{ }^{*}$, significant $(p<0.05)$ 


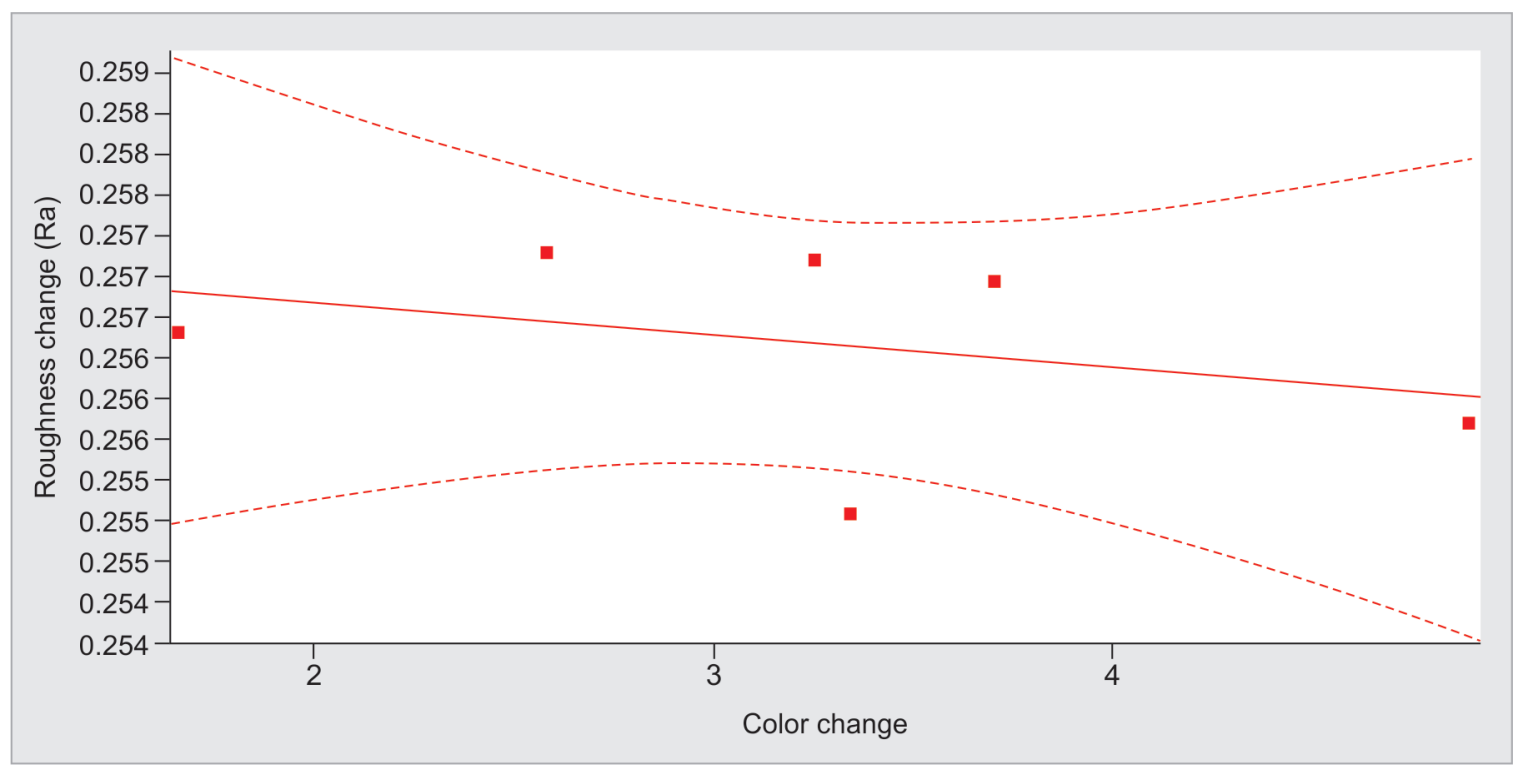

Fig. 3: A linear figure of correlation between total color change and roughness change

of color change was material-dependent. This result agrees with the findings of other researchers. ${ }^{30,37-40}$

Considering the effect of the resin remover on the surface roughness, the Te-Econom showed non-significant changes in the surface roughness after immersion in the resin remover. For the Tetric EvoCeram, the surface roughness was higher at the baseline and after 5-minutes immersion in the resin remover compared to values after 3- and 8-minutes immersion times. This agreed with the study of Tavangar et al., who found that changes in the surface roughness of resin composites by immersion in coffee, cola or distilled water depend on the type of material and polishing technique. ${ }^{33}$ This difference might be due to the chemical degradation of resin matrix by the resin remover in addition to degradation of a prepolymerized filler inside the Tetric EvoCeram. However, it should be noted that the actual change in roughness of Tetric EvoCeram ranged from $0.255 \mu \mathrm{m}$ to $0.257 \mu \mathrm{m}$ throughout test periods.

A comparison of surface roughness of both materials revealed that Tetric Evo Ceram had a comparable surface roughness to the Te-Econom except after 3 minutes; the surface roughness of Te-Econom was higher compared to the Tetric Evo Ceram. For the Te-Econom, the filler size range is larger $(0.04$ and $7 \mu \mathrm{m})$ than that of the Tetric Evo Ceram ( $40 \mathrm{~nm}$ and $3 \mu \mathrm{m}$ ). Previous studies examined the influence of four finishing methods (Astropol, Enhance, PoGo and SofLex discs) on the roughness of nanohybrid and microhybrid resin composite. They showed that before finishing, surface roughness between two materials differed significantly. However, after finishing, no significant differences in surface roughness was detected. ${ }^{41,42}$ In the present study, the materials were polished using Soflex discs before measurement of surface roughness. In addition, filler loading of Te-Econom and Tetric Evo Ceram is similar. ${ }^{43}$

In the present study, non-significant correlation was found between changes in color and surface roughness. This was in accordance with that observed by other researchers. ${ }^{21,40,44,45}$

For the hypothesis tested, the first hypothesis was partially accepted as the resin remover stained the tested resin composites, but did not significantly affect the surface roughness of the Te-Econom. The second hypothesis was partially accepted as increasing time from 3 to 8 minutes increased the staining of studied resin composites but did not affect the surface roughness of the Te-Econom. The third hypothesis was rejected as no correlation was found between changes in the color and surface roughness.

\section{Limitations of the Study}

This study examined only the color and roughness changes of $A 3$ shades, which make the results not applicable to other shades. ${ }^{7}$ Also, samples prepared in the present study were flat, but in a clinical situation, restoration had different configurations with different polishing techniques. Therefore, clinical studies are recommended.

\section{Conclusion}

Within the limitation of this study, it was concluded that the resin solvent changed the color of the microhybrid resin composite and nanocomposite. Increasing the immersion time to 8 minutes increased the color change for both resin composites. For surface roughness, the change was more material-dependent. There was no correlation between changes in color and surface roughness.

\section{Clinical Significance}

Resin solvent had potentials to be used for detection of resin composites from the tooth structure during removal of resin composite restoratives. Also, it could be used for identification of resin composites from the tooth structure and hence the removal of remnants of resin composite after orthodontic treatments.

\section{References}

1. Morikawa A, Ohmoto K, et al. Long term Clinical Observations on Two Posterior Restorative Composite Resins. Hiroshima Univ Dent J 1990;22:332-341.

2. Uo $M$, Okamoto $M$, et al. Rare earth oxide-containing fluorescent glass filler for composite resin. Dent Mater J 2005;24:49-52. DOI: 10.4012/ dmj.24.49.

3. Tani K, Watari F, et al. Discrimination between composite resin and teeth using fluorescence properties. Dent Mater J 2003;22:569-580. DOI: $10.4012 / d m j .22 .569$. 
4. Bush MA, Hermanson AS, et al. The use of ultraviolet LED illumination for composite resin removal: an in vitro study. Gen Dent 2010; 58:e214-e218.

5. Benthaus $S$, Du Chesne A, et al. A new technique for the post- mortem detection of tooth-coloured dental restorations. Int J Legal Med 1998;111:157-159. DOI: 10.1007/s004140050138.

6. Carson DO, Orihara Y, et al. Detection of white restorative dental materials using an alternative light source. Forensic Sci Int 1997;88: 163-168. DOI: 10.1016/S0379-0738(97)00115-1.

7. Meller C, Klein C. Fluorescence properties of commercial composite resin restorative materials in dentistry. Dent Mater J 2012;31:916-923. DOI: 10.4012/dmj.2012-079.

8. Meller C, Klein C. Fluorescence of composite resins: a comparison among properties of commercial shades. Dent Mater J 2015;34: 754-765. DOI: 10.4012/dmj.2014-219.

9. Hermanson AS, Bush MA, et al. Ultraviolet illumination as an adjunctive aid in dental inspection. J Forensic Sci 2008;53:408-411. DOI: 10.1111/j.1556-4029.2008.00657.x.

10. Abdallah MN, Light N, et al. Development of a composite resin disclosing agent based on the understanding of tooth staining mechanisms. J Dent 2014;42:697-708. DOI: 10.1016/j.jdent.2014.03.004.

11. Gaintantzopoulou M, Kakaboura A, et al. Colour stability of toothcoloured restorative materials. Eur J Prosthodont Restor Dent 2005;13:51-56.

12. Johnston WM. Color measurement in dentistry. J Dent 2009; 37(Suppl. 1):e2-e6. DOI: 10.1016/j.jdent.2009.03.011.

13. International Organization for Standardization. ISO/TR 28642 Dentistry - guidance on color measurement. Geneva: International Organization for Standardization; 2011.

14. Ghinea R, Perez MM, et al. Color difference thresholds in dental ceramics. J Dent 2010;38(Suppl. 2):e57-e64. DOI: 10.1016/ j.jdent.2010.07.008.

15. Abouelatta O. 3D Surface Roughness Measurement Using a Light Sectioning Vision System. Proceedings of the World Congress on Engineering 2010. vol. I.

16. Giacomelli L, Derchi G, et al. Surface roughness of commercial composites after different polishing protocols: An analysis with atomic force microscopy. Open Dent J 2010;4:191-194. DOI: 10.2174/1874210601004010191.

17. Horcas I, Fernandez R, et al. WSXM: a software for scanning probe microscopy and a tool for nanotechnology. Rev Sci Instrum 2007;78:013705. DOI: 10.1063/1.2432410.

18. Kakaboura A, Fragouli M, et al. Evaluation of surface characteristics of dental composites using profilometry, scanning electron, atomic force microscopy and gloss-meter. J Mater Sci Mater Med 2007;18: 155-163. DOI: 10.1007/s10856-006-0675-8.

19. Anusavice KJ. Phillips' Science of Dental materials. Applied Oral Science, 11th ed. St Louis: Elsevier, 2003 2009. pp. 108-112, vol. 17.

20. Khokhar ZA, Razzoog ME, et al. Color stability of restorative resins. Quintessence Int 1991;22:733-737.

21. Cengiz S, Yüzbaşioğlu E, et al. Color stability and surface roughness of a laboratory-processed composite resin as a function of mouthrinse. J Esthet Restor Dent 2015;27:314-321. DOI: 10.1111/jerd.12167.

22. Kuehni RG, Marcus RT. An experiment in visual scaling of small color differences. Color Res Appl 1979;4:83-91.

23. Lee YK, Lim BS, et al. Effect of surface conditions on the color of dental resin composites. J Biomed Mater Res 2002;63:657-663.DOI: 10.1002/ jbm.10383.

24. Reis AF, Giannini M, et al. Effects of various finishing system on the surface roughness and staining susceptibility of packable composite resins. Dent Mater 2003;19:12-18. DOI: 10.1016/S0109-5641(02)00014-3.

25. Cazzaniga G, Ottobelli M, et al. Surface properties of resin-based composite materials and biofilm formation: a review of the current literature. Am J Dent 2015;28:311-320.
26. Oysaed H, Ruyter IE. Water sorption and filler characteristics of composites for use in posterior teeth. J Dent Res 1986;65:1315-1318. DOI: $10.1177 / 00220345860650110601$.

27. da Silva MA, Fardin $A B$, et al. Analysis of roughness and surface hardness of a dental composite using atomic force microscopy and microhardness testing. Microsc Microanal 2011;17:446-451. DOI: 10.1017/S1431927611000250.

28. Telang A, Narayana IH, et al. Effect of staining and bleaching on color stability and surface roughness of three resin composites: An in vitro study. Contemp Clin Dent 2018;9:452-456.

29. Elwardani G, Sharaf AA, et al. Evaluation of colour change and surface roughness of two resin-based composites when exposed to beverages commonly used by children: an in-vitro study. Eur Arch Paediatr Dent 2018 Dec 26. DOI: 10.1007/s40368-018-0393-1.

30. Ren $Y F$, Feng $L$, et al. Effects of common beverage colorants on color stability of dental composite resins: the utility of a thermocycling stain challenge model in vitro. J Dent 2012;40(Suppl. 1):e48-e56. DOI: 10.1016/j.jdent.2012.04.017.

31. Mitra SB, Wu D, et al. An application of nanotechnology in advanced dental materials. J Am Dent Assoc 2003;134:1382-1390. DOI: 10.14219/ jada.archive.2003.0054.

32. Sideridou I, Tserki V, et al. Effect of chemical structure on degree of conversion in light-cured dimethacrylate-based dental resins. Biomaterials 2002;23:1819-1829. DOI: 10.1016/S0142-9612(01) 00308-8.

33. Tavangar M, Bagheri R, et al. Influence of beverages and surface roughness on the color change of resin composites. J Invest Clin Dent 2018;9:1-8. DOI: 10.1111/jicd.12333.

34. Gönülol N, Yılmaz F. The effects of finishing and polishing techniques on surface roughness and color stability of nanocomposites. J Dent 2012;40:e64-e70. DOI: 10.1016/j.jdent.2012.07.005.

35. Al-Shalan TA. In vitro staining of nanocomposites exposed to cola beverage. Pak Oral Dent J 2009;29:79-84.

36. lazzetti G, Burgess JO, et al. Color stability of fluoride containing restorative materials. Oper Dent 2000;25:520-525.

37. Villalta $\mathrm{P}, \mathrm{Lu} \mathrm{H}$, et al. Effects of staining and bleaching on color change of dental composite resins. J Prosthet Dent 2006;95:137-142. DOI: 10.1016/j.prosdent.2005.11.019.

38. Ardu S, Duc O, et al. Color stability of recent composite resins. Odontology 2017;105:29-35. DOI: 10.1007/s10266-016-0234-9.

39. Lemos CAA, Mauro SJ, et al. Influence of Mechanical and Chemical Degradation in the Surface Roughness, Gloss, and Color of Microhybrid Composites. J Contemp Dent Pract 2017;18:283-288. DOI: 10.5005/jp-journals-10024-2032.

40. YuH, Cheng SL, et al. Effects of cyclic staining on the color, translucency, surface roughness, and substance loss of contemporary adhesive resin cements. J Prosthet Dent 2018;120:462-469. DOI: 10.1016/ j.prosdent.2017.10.009.

41. Antonson SA, Yazici AR, et al. Comparison of different finishing/ polishing systems on surface roughness and gloss of resin composites. J Dent 2011;39:9-17. DOI: 10.1016/j.jdent.2011.01.006.

42. Da Costa J, Ferracane J, et al. The effect of different polishing systems on surface roughness and gloss of various resin composites. J Esthet Restor Dent 2007;19:214-224. DOI: 10.1111/j.1708-8240.2007. 00104.x.

43. Dede DÖ, Şahin O, et al. Effect of sealant agents on the color stability and surface roughness of nanohybrid composite resins. J Prosthet Dent 2016;116:119-128. DOI: 10.1016/j.prosdent.2015.11.024.

44. Yikilgan I, Akgul S, et al. The effects of fresh detox juices on color stability and roughness of resin-based composites. J Prosthodont 2019;28(1):e82-e88. DOI: 10.1111/jopr.12759.

45. Hwang S, Chung SH, et al. Influence of acid, ethanol, and anthocyanin pigment on the optical and mechanical properties of a nanohybrid dental composite resin. Materials (Basel) 2018;18:11-17. 